\title{
An unhealthy disregard
}

\author{
Major pharmaceutical firms are regularly slapped with huge fines for illegally promoting off-label drug use. But as \\ long as the sales of these drugs dwarf the size of the fines, companies will continue to skirt the law.
}

n April, AstraZeneca agreed to pay $\$ 520$ million in US federal fines, coming after allegations of illegal marketing of Seroquel, an antipsychotic agent approved for the treatment of schizophrenia and bipolar disorder. The case is the latest example of corporate greed sullying the public image of the pharmaceutical industry.

The US government contends that AstraZeneca illegally promoted the use of Seroquel for individuals with a range of diseases and disorders-such as attention deficit hyperactivity disorder, post-traumatic stress disorder and Alzheimer's disease-for which it has not been proven safe or effective. The fine will help defray the excessive cost to Medicaid programs that reimbursed the off-label prescriptions. The government also alleges that AstraZeneca paid illegal kickbacks to doctors who were listed as authors of studies on Seroquel to which they did not contribute or who promoted off-label uses of Seroquel to other medical professionals at conferences sponsored by the company.

More than 25,000 civil suits are still pending against AstraZeneca, accusing the company of hiding the health risks of Seroquel use. Specifically, Seroquel use is associated with weight gain and an increased risk of diabetes, as well as death, particularly in certain elderly patients. The risks are cited within the labeling information, and, thus far, a number of cases against AstraZeneca have been dismissed. But the US Food and Drug Administration (FDA) found that promotional material for Seroquel distributed by the company downplayed the risk of these and other serious side effects. AstraZeneca denies any wrongdoing.

Off-label drug marketing occupies a peculiar niche between greed and hope. The FDA allows doctors to prescribe approved drugs or medical devices for unapproved indications, acknowledging that they might be of benefit to additional patient populations. For example, thalidomide was regularly prescribed off label for the treatment of patients with multiple myeloma before its approval for this indication. And Avastin, approved for the treatment of certain cancers, is used off label to treat macular degeneration.

The FDA also permits drug manufacturers to distribute to physicians scientific-but not promotional-literature reporting clinical studies of off-label use, ostensibly to help inform the decision making of prescribing physicians, but effectively serving to expand a drug's market. The overt marketing of approved drugs and devices for unapproved uses is illegal.

In 2009, the FDA released good practices guidelines for the distribution of medical literature on unapproved uses for approved drugs and medical devices, with the aim of presenting a balanced view of available information to healthcare professionals who might consider prescribing these products for off-label use (http://www.fda.gov/ regulatoryinformation/guidances/ucm125126.htm and http://www. nature.com/nm/journal/v14/n1/full/nm0108-1.html).

Not surprisingly, the guidelines recommend the distribution of reprints of peer-reviewed articles but not of work that is heavily influenced by the manufacturer of the drug or device in question. The publications should accurately reflect the larger body of literature on the product and be accompanied by a contradictory study, should one exist. And any information regarding serious safety risks associated with the described off-label use should be disclosed. In this manner, the FDA hopes that off-label use of medical products is conducted with the welfare of the patient firmly in mind, while keeping the sales drive of the manufacturer in check. But the guidelines are not legally binding and can't be policed or enforced. The behavior of many pharmaceutical companies suggests that they are also largely ignored.

AstraZeneca's settlement follows on the heels of similar federal investigations in the last three years of illegal off-label marketing of a number of drugs by Pfizer, Eli Lilly, Bristol-Myers Squibb and Novartis, with fines totaling more than $\$ 4$ billion. In 2009, Pfizer was fined $\$ 2.3$ billion - the largest amount to date and the fourth settlement against Pfizer since 2002 - for the illicit promotion of four different drugs. One of these drugs, Bextra, was ultimately pulled from the market because its risks, including death, outweighed its benefits. The companies' actions clearly indicate that the current size of the fines is not an effective deterrent to harmful marketing practices. It's worth noting that in 2009 , AstraZeneca made $\$ 32.8$ billion in sales-4.9 billion from Seroquel alone-and Pfizer's revenues topped more than $\$ 50$ billion.

Promotion of a drug by a pharmaceutical company's sales force should not take the place of objective evaluation by a regulatory agency. Although there is potential medical value to off-label drug use, unethical behavior that unduly exposes individuals to risks associated with medications-risks that are suppressed or insufficiently conveyed to the prescribing physician and patient-must be stopped. If the current system of fines and corporate integrity agreements is not working, stronger measures that significantly affect a company's bottom line should be implemented, such as barring a company from receiving drug sale reimbursements from governmental health programs. And although the pharmaceutical companies might argue that increasing punitive measures that could limit their ability to produce drugs is a disservice to patients, we would argue that protecting patients from risk of harm is not. 